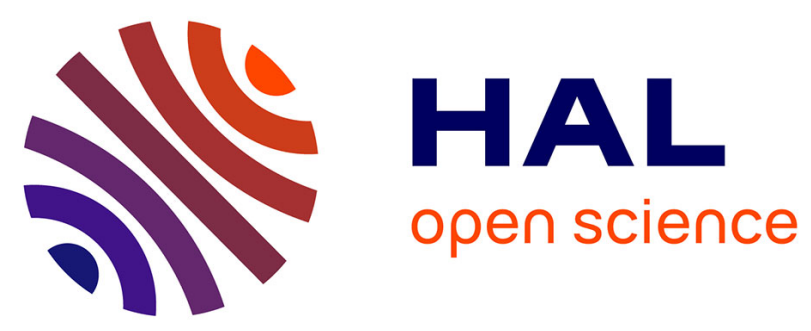

\title{
NIR and MIR Absorption of Ultra-Black Silicon(UBS) Application To High Emissivity, All-Silicon, Light Source
}

Sreyash Sarkar, Ahmed A Elsayed, E. Nefzaoui, Jérémie Drevillon, Philippe

Basset, Frédéric Marty, Momen Anwar, Yiting Yu, Jiancun Zhao, Xichen

Yuan, et al.

\section{To cite this version:}

Sreyash Sarkar, Ahmed A Elsayed, E. Nefzaoui, Jérémie Drevillon, Philippe Basset, et al.. NIR and MIR Absorption of Ultra-Black Silicon(UBS) Application To High Emissivity, All-Silicon, Light Source. 2019 IEEE 32nd International Conference on Micro Electro Mechanical Systems (MEMS), Jan 2019, Seoul, South Korea. hal-02182951

\section{HAL Id: hal-02182951 \\ https://hal.science/hal-02182951}

Submitted on 14 Jul 2019

HAL is a multi-disciplinary open access archive for the deposit and dissemination of scientific research documents, whether they are published or not. The documents may come from teaching and research institutions in France or abroad, or from public or private research centers.
L'archive ouverte pluridisciplinaire HAL, est destinée au dépôt et à la diffusion de documents scientifiques de niveau recherche, publiés ou non, émanant des établissements d'enseignement et de recherche français ou étrangers, des laboratoires publics ou privés. 


\title{
NIR AND MIR ABSORPTION OF ULTRA-BLACK SILICON (UBS). APPLICATION TO HIGH EMISSIVITY, ALL-SILICON, LIGHT SOURCE
}

\author{
Sreyash Sarkar ${ }^{1}$, Ahmed A. Elsayed ${ }^{1,2}$, Elyes Nefzaoui ${ }^{1}$, Jérémie Drévillon ${ }^{3}$, Philippe Basset ${ }^{1}$, \\ Frédéric Marty ${ }^{1}$, Momen Anwar ${ }^{2}$, Yiting Yu ${ }^{4}$, Jiancun Zhao ${ }^{4}$, Xichen Yuan ${ }^{4}$, ZhongZhu Liang ${ }^{5}$ \\ Diaa Khalil ${ }^{2,6}$, Yasser M. Sabry ${ }^{2,6}$, and Tarik Bourouina ${ }^{1,6}$ \\ ${ }^{1}$ Université Paris-Est, Laboratoire ESYCOM, ESIEE Paris, Noisy-le-Grand Cedex, France \\ ${ }^{2}$ Electronics and Electrical Com. Depart., Faculty of Eng., Ain Shams University, Cairo, Egypt. \\ ${ }^{3}$ Institut Pprime, CNRS, Université de Poitiers, ISAE-ENSMA, Futuroscope Chasseneuil, France \\ ${ }^{4}$ Northwestern Polytechnical University, Xi'an, China \\ ${ }^{5}$ State Key Laboratory of Applied Optics, Changchun Institute of Optics, Fine Mechanics and \\ Physics, Chinese Academy of Sciences, Changchun, Jilin, China \\ ${ }^{6} \mathrm{Si}-$ Ware Systems, 3 Khalid Ibn Al-Waleed St., Heliopolis, Cairo, Egypt.
}

\begin{abstract}
We present the Near-Infra-Red (NIR) and MidInfrared (MIR) absorption properties of Ultra-Black Silicon obtained by wafer-level cryogenic plasma processing. We found that when using highly-doped silicon, the spectral range of near-unity full absorption of light is extended from the visible range till a wavelength of $10 \mu \mathrm{m}$. This MIR wavelength range coincides with that of the maximum of black-body radiation from room temperature up to a few thousand Kelvin. Therefore, according to Kirchhoff's Law, we take advantage of the enhanced properties of black silicon to realize ultracompact light-sources of high efficiency, which are operated in combination with a MEMS-FTIR spectrometer.
\end{abstract}

\section{INTRODUCTION}

Black Silicon (BSi) has become nowadays, a wellestablished micro-nano-structured silicon surface that can be obtained by different techniques including cryogenic plasma [1] as considered in this work. BSi exhibits fascinating wetting and optical properties. In particular, due to its specific morphology, it is well-known for its excellent absorption of almost $100 \%$ of incident light [12], hence its name is Black according to its color to the naked eye. However, little is known about such optical properties, when considering other spectral ranges than the visible.

In this work, we started exploring the absorption properties of $\mathrm{BSi}$ in the infrared range, covering both the Near Infra-Red (NIR) and Mid-Infra-Red (MIR) spectral ranges from $1.5 \mu \mathrm{m}$ until $10 \mu \mathrm{m}$ wavelengths. Surprisingly excellent absorption, below $0.4 \%$ was found in this range - and even below $0.1 \%$ when considering the range from 1 to $8.5 \mu \mathrm{m}$. This behavior is exhibited especially when considering high-doping, leading to Ultra-Black Silicon (UBS) in the MIR. Then, in the second part of this paper, we took advantage of this remarkable property to explore the application of UBS to light-emitting devices based on black-body radiation.

\section{RESULTS}

\section{Broadband Light Absorption of Ultra-} Black Silicon extending to the Mid-Infra-Red

In our experiments, we considered two samples with low and high dopings respectively. BSi was produced by wafer-level cryogenic plasma [1-2]. Two additional flat samples with same doping levels were also taken as references. Figure 1 shows the spectral responses of those four samples, recorded in the infrared spectral range from $1.5 \mu \mathrm{m}$ to $10 \mu \mathrm{m}$ at room temperature.

As a reminder, Figure 2 also recalls the typical responses recorded in the visible range; as most of the time, such a curve shows an increase of reflectance at the highest wavelengths, which also suggests that absorption should deteriorate if we increase the wavelength further. But surprisingly, this does not happen in our results shown in figure 1 . On the contrary, one can see that reflectance is kept very low, below $1 \%$ up to $10 \mu \mathrm{m}$. For the highly doped silicon, reflectance remains even below $0.1 \%$ up to $7.5 \mu \mathrm{m}$ and then starts increasing up to $0.4 \%$ at $10 \mu \mathrm{m}$. Such small numbers in this specific wavelength range are of paramount importance, especially when considering various applications.

Even though it was already known that high doping can lead to increased light absorption, especially when combined with Black Silicon [3-4], it is the first time evidence that this behavior extends to the Mid Infrared is given. Moreover, it is also the first time that such low reflectivity levels, below $0.1 \%$ are demonstrated. These rather surprising results led us to investigate the possible origins of this astonishing behavior, further. 


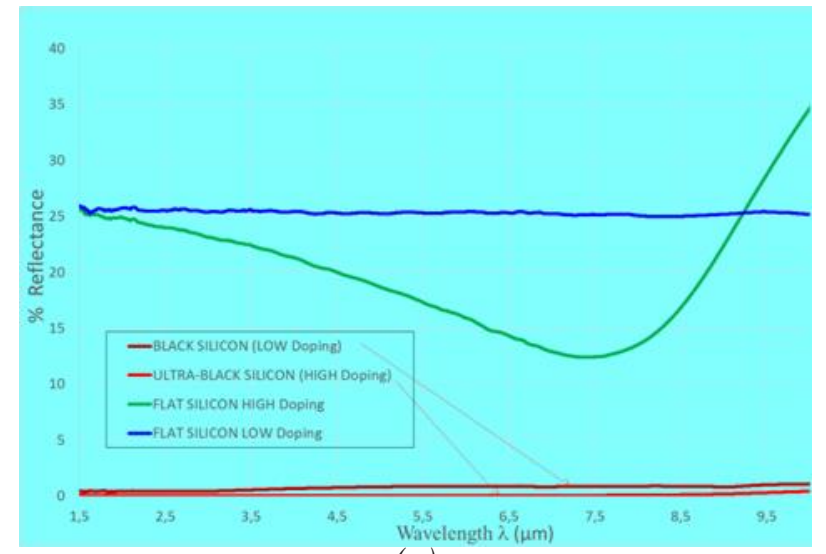

(a)

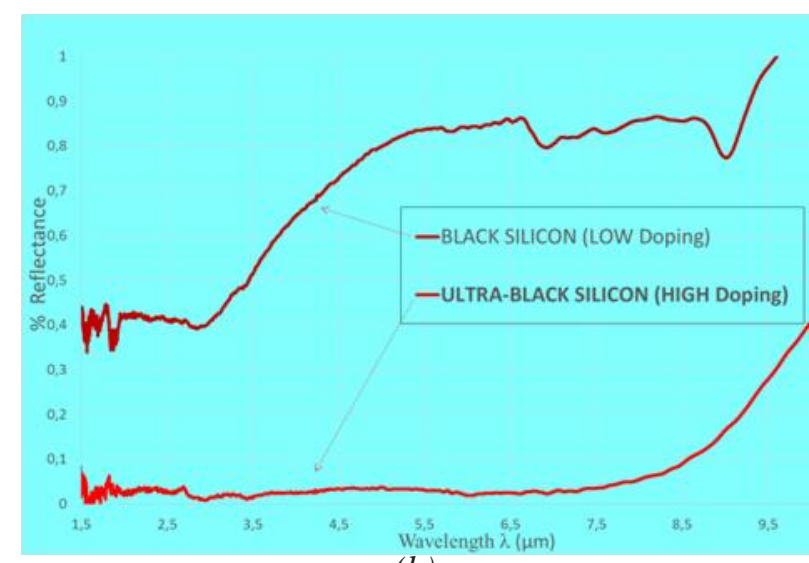

(b)

Figure 1: (a) Spectral reflectance in the Near- and Midinfrared ranges comparing low-doping black silicon and high-doping black silicon, as well as two flat samples taken as a reference for both low doping and high doping. (b) Zoom on the two black silicon samples, illustrating the surprisingly very low reflectance levels below $0.1 \%$.

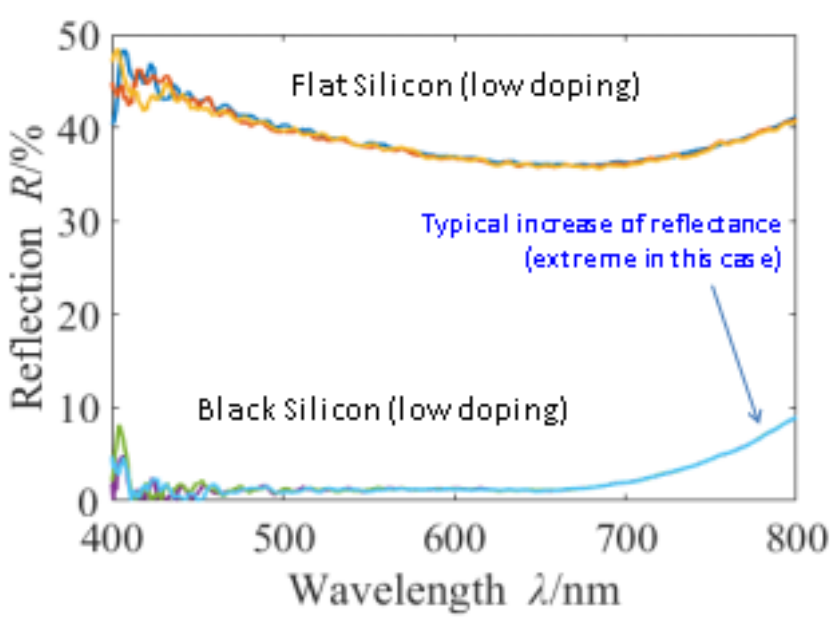

Figure 2: Typical spectral response of (low-doping) black silicon, illustrating that the reflectance, even low, has a trend to increase in the upper visible range.

\section{Application to Broadband Light Source Based on Black-Body Emission}

Indeed, the most relevant application relates to Black-body light-emitting devices. We have to recall first that according to the Kirchhoff's law of thermal radiation [5], emissivity is equal to absorptivity at a given wavelength and temperature, which means that any material that is excellent for light absorption will also be excellent for light emission.

Therefore, in the second part of this work, we introduce measurement results on such a highperformance light-emitting device based on black silicon [6-7]. Here, a resistive heating element is implemented based on a platinum resistor integrated onto the silicon surface (Figure 3). This enabled reaching temperature levels up to $800^{\circ} \mathrm{C}$ with voltage levels not exceeding 50 Volts.

Typical spectra obtained from such a device are illustrated in Figure 4. It is worth-mentioning that those spectra were recorded with a MEMS-FTIR spectrometer operating in the mid-infra-red range (Figure 5), suggesting that our UBS-based light source can be combined with such a spectrometer, for instance for chemical analysis, in an ultra-compact fashion, hence extending the application scope of UBS.

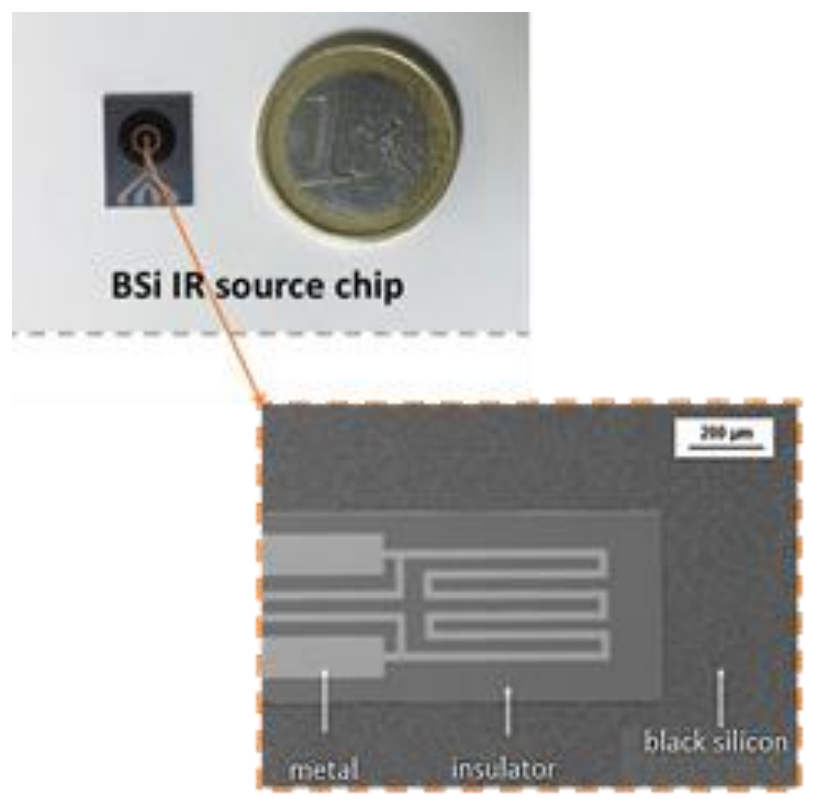

Figure 3: Photo of a platinum resistive heater integrated onto a black silicon surface, to produce a black-body radiation light-source. 


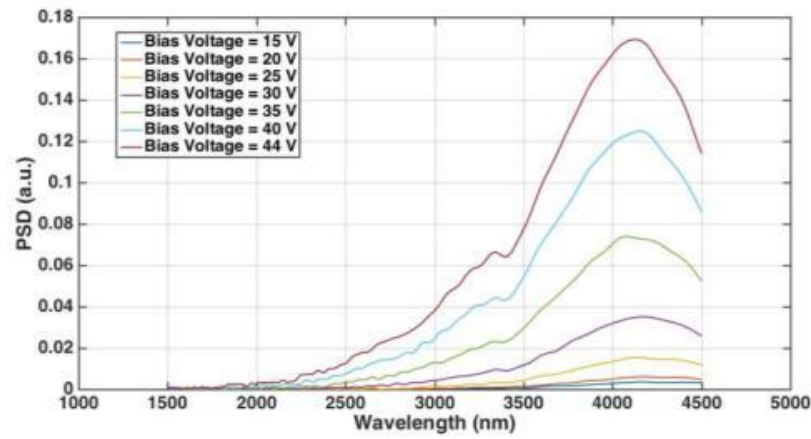

Figure 4: Spectra of infra-red radiation emitted by the heated black-silicon sample at different temperatures, reached through control of electrical voltage levels on the platinum resistive heater shown in Figure 3.

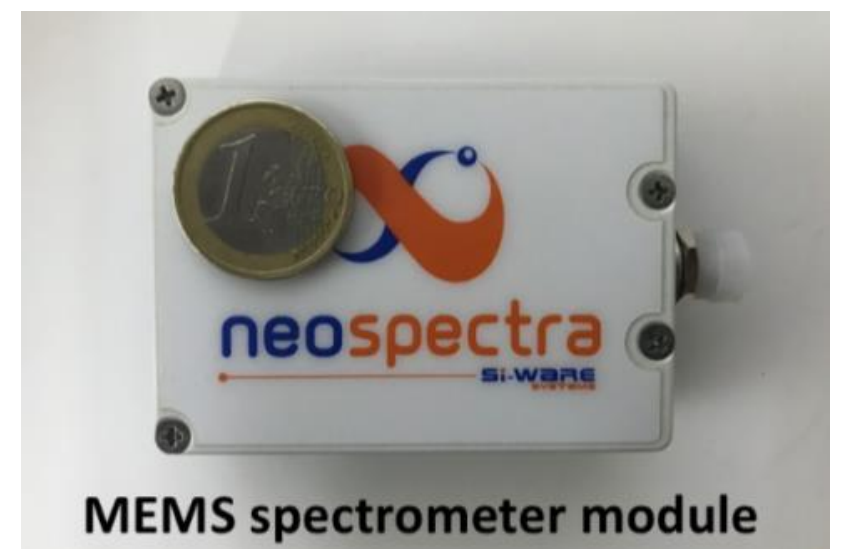

Figure 5: MEMS-based FTIR spectrometer operating in the mid-infra-red range, used to record the spectra shown in Figure 4. This suggests that the UBS-based light source can be combined with such spectrometer, for instance for chemical analysis, in an ultra-compact fashion.

\section{CONCLUSIONS}

In conclusion, we have explored the black silicon absorption properties in the mid-infra-red spectral range up to a wavelength of $10 \mu \mathrm{m}$. Using Highly Doped Silicon we obtained Ultra-Black Silicon with reflection levels below $0.1 \%$ on an ultra-broadband spectral range extending from $1.5 \mu \mathrm{m}$ to $8.5 \mu \mathrm{m}$. This exceptional behavior is not ascribed to the high level of doping of the nanostructured surface.

The exceptionally high absorptivity levels also translate into high emissivity of Ultra-Black Silicon. This was taken as advantage to demonstrate a high-efficiency broad-band light source based on black-body emission, operated by heating the ultra-black silicon by means of a platinum resistive element.

\section{ACKNOWLEDGEMENT}

This work was supported by the I-SITE FUTURE Initiative (reference ANR-16-IDEX-0003) in the frame of the project NANO-4-WATER.

\section{REFERENCES}

[1] K. N. Nguyen, P. Basset, F. Marty, Y. LeprinceWang, and T. Bourouina "On the optical and morphological properties of microstructured Black Silicon obtained by cryogenic-enhanced plasma reactive ion etching", Journal of Applied Physics 113, 194903 (2013)

[2] D. Abi Saab, P. Basset, M.J. Pierotti, M.L. Trawick and D.E. Angelescu, «Static and Dynamic Aspects of Black Silicon Formation », Phys. Rev. Lett. 113, 265502 (2014).

[3] M. Steglich, D. Lehr, S. Ratzsch, T. Käsebier, F. Schrempel, E-B. Kley, A. Tünnermann. « An ultrablack silicon absorber ». Laser \& Photonics Reviews 8, L13-L17 (2014).

[4] A.E. Elsayed, Y.M. Sabry, F. Marty, T. Bourouina, D. Khalil, "Optical modeling of black silicon using an effective medium/multi-layer approach", Optics Express Vol. 26, No. 10 | (2018) 13443

[5] Kirchhoff, G. (1860). "On the relation between the radiating and absorbing powers of different bodies for light and heat". Philosophical Magazine. Series 4. 20: 1-21. G. Minas, J. Martins, J. Ribeiro, R. Wolfenbuttel, J. Correia, Sens. Actuators A, 110 (2004) pp.33-38.

[6] M. Anwar, Y. Sabry, P. Basset, F. Marty, T. Bourouina, D. Khalil, «Black silicon-based infrared radiation source ». in Silicon Photonics XI 9752, 97520E SPIE Photonics West (2016), San Francisco, California.

[7] Y. M. Sabry, D. Khalil, T. Bourouina, \& M. Anwar, Structured silicon-based thermal emitter. (2017) Patent US9793478B2

\section{CONTACT}

Tarik BOUROUINA, tel: +33 14592 6692;

Tarik.bourouina@esiee.fr 